\title{
Anxiety disorder in elderly persons with chronic pain: frequency and associations
}

Kate Adriany da Silva Santos'

Maysa Seabra Cendoroglo ${ }^{1}$ Fania Cristina Santos'

\section{Abstract}

Objectives: to evaluate the frequency of anxiety disorders in older elderly persons with chronic pain and identify associated factors. Method: a descriptive, analytical and cross section study of the "Projeto Longevos" ("Long-Lived Elderly Persons Project") was carried out, featuring elderly persons living in the community who were aged 80 or over. Older elderly persons with chronic pain were selected, and data regarding their sociodemographic characteristics and factors related to pain was gathered, especially with regard to the multidimensional nature of pain, according to the "Geriatric Pain Measure-p" (GPM-p). Self-perception of health was also recorded and functionality assessments were carried out, along with the screenings for depression and anxiety disorders, according to the Geriatric Depression Scale and the State-Trait Anxiety Inventory, respectively. Associations were analyzed by Pearson correlation, the ANOVA Test and Tukey multiple comparisons. Results: the sample was composed of 41 elderly persons with a mean age of 85.7 years, most of whom were female, white, widowed and had a low education. A high prevalence of anxiety disorders was observed, being 53.6\% and 68.3\%, respectively, for trait and state anxiety. A significant, but not high, correlation was found between the anxiety trait and chronic pain according to the GPM-p ( $\mathrm{r}=31.5 \% ; p=0.048)$, and there was a significant and high correlation between the same type of anxiety and depression $(\mathrm{r}=61.3 \% ; p<0.001)$. Conclusion: anxiety disorders were very prevalent in older elderly persons with chronic pain, and these correlated significantly with pain and depression, which could justify the need for varied multidisciplinary therapeutic measures against the persistent pain conditions of the elderly.

\footnotetext{
Universidade Federal de São Paulo, Serviço de Dor e Doenças Osteoarticulares, Disciplina de Geriatria
} e Gerontologia. São Paulo, SP, Brasil.

Correspondence

Fania Cristina Santos

E-mail: faniacs@uol.com.br
Keywords: Chronic pain. Elderly. Anxiety. Depression. 


\section{INTRODUCTION}

Increased life expectancy has resulted in a greater number of elderly people with chronic diseases. These diseases are often associated with chronic pain, which in turn can lead to functional impairment, psychological distress (anxiety and depression), and sleep deprivation ${ }^{1}$.

Around $80 \%$ of people with chronic pain report that it interferes in their activities of daily living, while about two-thirds of such individuals indicate that pain negatively impacts their personal relationships ${ }^{2}$.Chronic pain also has biopsychosocial consequences, emphasizing the magnitude of the problem, especially among elderly persons with a greater prevalence of such pain. A Brazilian study found that $21.7 \%$ of patients with chronic pain suffered mood disorders ${ }^{3}$. Asmundson and $\mathrm{Katz}^{4}$, reviewing three studies about chronic pain and anxiety, found that $20 \%$ to $70 \%$ of patients with panic disorder reported suffering from chronic pain. More recently, it was found that the coexistence of depressive or anxiety disorders with chronic pain was associated with deteriorating clinical evolution, greater use of medical services and increased health care expenses ${ }^{5}$.

The period between 2000 and 2015 saw a growth in studies related to chronic pain and anxiety disorders. Few of these studies, however, involve elderly individuals, especially older elderly persons ${ }^{4}$, the fastest growing population in the world.

The objective of the present study was to evaluate the prevalence of anxiety disorders in elderly people with chronic pain and analyze the factors associated with such disorders.

\section{METHOD}

A descriptive, analytical and cross-sectional study was carried out. It was part of the "Projeto Longevos" ("the Long-Lived Elderly Persons Project") of the Geriatrics and Gerontology department of the Universidade Federal de São Paulo (the Federal University of São Paulo) (UNIFESP), which has monitored, since 2010, elderly persons aged 80 or over of both genders living in the community in the city of São Paulo, in São Paulo state. The inclusion factor was functional independence in basic activities of daily living (BADL), and the exclusion factors were loss of autonomy according to clinical evaluations or cognitive tests, and the presence of severe acute or chronic decompensated illness.

A convenience sample of elderly persons with chronic pain from the "Projeto Longevos" was employed. The sample calculation, which included a statistical power of $80 \%$ and an alpha error of $5 \%$, and was based on an anxiety disorder frequency of $20 \%$ (the minimum anxiety disorder frequency identified in a significant study on the subject of pain) ${ }^{4}$ and a universe of 69 elderly persons (the recent quantity of older elderly persons with chronic pain in the "Projeto Longevos") ${ }^{6}$, calculated a total of $\mathrm{N}$ of 41 . Elderly patients with chronic pain that had lasted for at least six months and an intensity greater than or equal to three, according to the visual numeric scale (VNS) for pain ${ }^{7}$ were included in the study. Individuals with sensory or limiting cognitive deficits, debilitating or potentially serious or fatal clinical illnesses, a history of hospitalization in the last three months, or pain with a neoplastic etiology were excluded. Evaluations took place between April and December 2013.

Sociodemographic data (age, skin color/ ethnicity, marital status and schooling) was collected, as well as data related to pain, such as location, duration, frequency and intensity according to the VNS, which evaluates pain on a scale from 0 to 10 (0 representing "no pain" and 10 indicating "worst pain imaginable") $)^{7}$. Pain was evaluated in a multidimensional manner according to the Geriatric Pain Measure-p (GPM-p), an instrument that has undergone cross-cultural adaptation for use in Brazil and has had its psychometric properties evaluated, meaning that it is considered reliable and valid for use among the elderly ${ }^{8}$. This instrument allows pain to be considered in accordance with its various dimensions: sensory-discriminative, motivational-affective and cognitive-evaluative. As such, the tool makes it possible to evaluate pain profiles beyond mere intensity, but also through the nature, discomfort and related disengagement of the pain (such as social isolation due to pain related to walking and more vigorous activity) ${ }^{9}$. 
The functionalities that measure the capacity to execute BADL and instrumental activities of daily living (IADL) were evaluated using the $\mathrm{Katz}^{10}$ and Lawton $^{11}$ scales, respectively; as well as the selfperceptions of health (classified as poor, fair, good or very good) ${ }^{12}$, and the presence of depressive disorders. The latter were evaluated using the Geriatric Depression Scale (GDS), which has a sensitivity of $81 \%$ and a specificity of $71 \%$ for the diagnosis of depression in the elderly, when a total score of 5 points is obtained ${ }^{13}$.

The tracking of anxiety disorders was carried out according to the State-Trait Anxiety Inventory (STAI) of Spielberger et al. $^{14}$, one of the most commonly used tools for the quantification of subjective components related to anxiety. It is simple to apply and there is considerable evidence of the validity and reliability of the test. The STAI is based on a theoric model of two distinct components divided into two subscales: one which evaluates anxiety as a state (STAI-S), referring to a transient emotional picture where feelings of apprehension and tension are consciously perceived, accompanied by an increase in the activity of the autonomic nervous system; and another that evaluates anxiety as a trait (STAI-T), referring to "tendencies" in reacting to situations perceived as threatening, or in other words, "acquired behavioral dispositions"15. The two subscales are scored separately, with a minimum and maximum score of 20 and 80, respectively, with higher scores indicating more intense levels of anxiety. The cut-off points are: $<33$, which is equivalent to the absence of symptoms of anxiety or mild anxiety, between 33 and 49, equivalent to average anxiety, and $>49$, equivalent to a high level of anxiety.

In the present study, the prevalence of anxiety disorders was obtained based on participants with moderate to severe symptomatology, who were then grouped together ${ }^{16}$. Davidson et $\mathrm{al}^{17}$. proposed a cut-off point for STAI scores of $>39$ to identify the presence of an anxiety disorder, a classification used in the present study.

Statistical analysis involved the calculation of mean, standard deviation, median, minimum and maximum values, as well as the confidence interval for the quantitative variables. For associations with the STAI, the Pearson correlation, Anova test and Tukey's multiple comparisons were used. A level of significance of $5 \%$ was adopted.

The project was approved by the Research Ethics Committee of the Universidade Federal de São Paulo (the Federal University of São Paulo) (UNIFESP), under $n^{\circ}$ 250.104/2013, and all the participants signed a Free and Informed Consent Form.

\section{RESULTS}

The sample consisted of 41 elderly persons with a mean age of 85.7 years (ranging from 80 to 96 years), most of whom were female $(85.3 \%)$, with white skin color/ethnicity (63.4\%), widowed (58.5\%), and had a low level of schooling (56.0\% had only a primary level education) (Table 1).

The majority of the participants were functionally independent in ADL (97.6\%) and IADL (51.2\%). They self-perceived their health to be good or fair (43.9\% and $42.7 \%$ respectively) (Table 1 ).

Depressive disorders were present in $36.6 \%$ of the elderly persons. The majority referred to their chronic pain as being severe in intensity, as defined by the VNS (56.1\%), and moderate according to the GPM-p (53.7\%) classification.

Table 1. Sociodemographic characteristics and general health conditions of elderly persons. São Paulo. state of São Paulo. 2013.

\begin{tabular}{ll}
\hline Variables & $\mathrm{n}(\%)$ \\
\hline Age (years) & \\
80 & $3(7.3)$ \\
$81-85$ & $17(41.5)$ \\
$86-90$ & $17(41.5)$ \\
$>90$ & $4(9.7)$ \\
\hline
\end{tabular}


continued from table 1

\begin{tabular}{ll}
\hline Variables & $\mathrm{n}(\%)$ \\
\hline Gender & $35(85.3)$ \\
Female & $6(14.7)$ \\
Male & \\
\hline Skin color/ethnicity* & $2(4.9)$ \\
Black/Afro-Brazilian & $26(63.4)$ \\
White/Caucasian & $2(4.9)$ \\
Yellow/Asian-Brazilian & $11(26.8)$ \\
Brown/Mixed Race Brazilian & \\
Marital Status & $2(4.9)$ \\
Cohabiting & $10(24.2)$ \\
Married & $1(2.4)$ \\
Separated & $4(9.8)$ \\
Single & $24(58.5)$ \\
Widowed & \\
Schooling & $6(14.6)$ \\
Illiterate & $23(56)$ \\
Primary school (1-4 years) & $6(14.6)$ \\
Elementary school (5-8 years) & $2(5)$ \\
High school (9-11 years) & $4(9.8)$ \\
Higher education (>11 years) & \\
Functionality - ADL & $1(2.4)$ \\
Partial dependency & $40(97.6)$ \\
Independent & \\
\hline Functionalit - IADI & \\
\hline
\end{tabular}

Functionality - IADL

Severe dependence

Moderate dependence $13(31.7)$

Mild dependence 6 (14.6)

Independent $21(51.2)$

Self-perceived health

\begin{tabular}{ll} 
Poor & $4(9.8)$ \\
Fair & $17(41.5)$ \\
Good & $18(43.9)$ \\
Very good & $2(4.9)$ \\
\hline Depression - GDS & \\
No depression & $26(63.4)$ \\
Depression & $15(36.6)$
\end{tabular}

Pain - VNS intensity

Mild

Moderate

Severe

Pain - GPM-p classification

Mild

Moderate

Severe $23(24.4)$

* Instituto Brasileiro de Geografia e Estatística (Brazilian Institute of Geography and Statistics) (IBGE); ADL: basic activity of daily living; IADL: instrumental activity of daily living; GDS: geriatric depression scale; VNS: visual numeric scale; GPM-p: Geriatric Pain Measure-p. 
According to the STAI of Spielberger et al. ${ }^{14}$ the prevalences of anxiety disorder were $73.2 \%$ and $68.3 \%$, respectively, for the STAI-T and STAI-S. In terms of classifications, the frequencies of severe disorder were around 19.6\% (STAI-T) and 4.9\% (STAI-S) (Table 2). According to the STAI score cut-off point of Davidson et al. ${ }^{17}$, the prevalences of anxiety were lower (58.5\% STAI-T and 39.0\% STAI-S)

When analyzing the correlations between anxiety disorders and the variables in the study, a significant and positive association was identified between the STAI-T and chronic pain as defined by the GPM-p. However, such association was considered low $(\mathrm{r}=31.5 \% ; \mathrm{p}=0.048)$, with values between 20 and $40 \%$ (Table 3 ).

"Trait" type anxiety disorders were significantly and positively associated with the variable of depression. This correlation was considered to be good $(\mathrm{r}=61.3 \%$, $\mathrm{p}<0.001$ ), with values between 60 and $80 \%$

Statistically significant correlations between anxiety and functionality (ADL and IADL) and self-perceived health were not observed.

Table 2. Trait and State anxiety disorders, according to the STAI of Spielberger et al14 and the STAI cut-off point of Davidson et al17. São Paulo, state of São Paulo, 2013.

\begin{tabular}{|c|c|c|c|}
\hline \multicolumn{2}{|l|}{ Variables } & $\begin{array}{l}\text { Anxiety-Trait } \\
\mathrm{N}(\%)\end{array}$ & $\begin{array}{l}\text { Anxiety-State } \\
\mathrm{N}(\%)\end{array}$ \\
\hline \multicolumn{4}{|l|}{ STAI-T } \\
\hline Mean and standard deviation & $40,8( \pm 10,70)$ & & \\
\hline Median (Q25-Q75) & $40(32-46)$ & & \\
\hline Minimum & 22 & & \\
\hline Maximum & 65 & & \\
\hline \multicolumn{4}{|l|}{ STAI-S } \\
\hline Mean and standard deviation & $36,7( \pm 7,6)$ & & \\
\hline Median (Q25-Q75) & $37(32-42)$ & & \\
\hline Minimum & 20 & & \\
\hline Maximum & 51 & & \\
\hline \multicolumn{4}{|l|}{ STAI - Spielberger et al.14 score. } \\
\hline$<33$ : Anxiety absent or mild & & $11(26,8)$ & $11(26,8)$ \\
\hline 33-39: Moderate anxiety & & $22(53,6)$ & $28(68,3)$ \\
\hline$>39$ : Severe anxiety & & $8(19,6)$ & $2(4,9)$ \\
\hline \multicolumn{4}{|l|}{ STAI - Davidson et al. score17. } \\
\hline >39: Anxiety present & & $24(58,5)$ & $16(39,0)$ \\
\hline
\end{tabular}

STAI-T: Anxiety Inventory-Trait; STAI-S: Anxiety Inventory-State

Table 3. Associations between anxiety, pain, depression and functionality. São Paulo, state of São Paulo, 2013.

\begin{tabular}{|c|c|c|c|c|}
\hline \multirow[t]{2}{*}{ Variables } & \multicolumn{2}{|l|}{ Anxiety-Trait } & \multicolumn{2}{|l|}{ Anxiety-State } \\
\hline & Correlation (r) (\%) & $p$-value & Correlation (r) (\%) & $p$-value \\
\hline Pain - VNS intensity & $-17,0$ & 0,288 & $-29,3$ & 0,063 \\
\hline Pain - GPM-p classification & 31,5 & 0,048 & 11,2 & 0,493 \\
\hline Depression - GDS & 61,3 & $<0,001$ & 21,6 & 0,175 \\
\hline Functionality - BADL & $-29,5$ & 0,061 & 2,8 & 0,864 \\
\hline Functionality - IADL & $-26,0$ & 0,100 & $-19,8$ & 0,215 \\
\hline
\end{tabular}

NVS: numeric visual scale; GPM-p: Geriatric Pain Measure-p; GDS: geriatric depression scale; BADL: basic activity of daily living; IADL: instrumental activity of daily living. 


\section{DISCUSSION}

A sample composed of 41 elderly people was obtained, most of whom were women. This corroborates the theory of the feminization of aging, especially among those aged 80 years or more $^{18,19}$. It has been suggested that women have higher risks of chronic pain, and in addition, describe more somatic disorders than men ${ }^{19,20}$. Chronic pain was considered severe when evaluated in a unidimensional manner by the VNS $(56.1 \%)$, which refers only to the intensity of pain, and moderate and severe when evaluated in a multidimensional manner by the GPM-p (78, 2\%). Chronic pain defined by the GPM-p correlated significantly with the STAI-T, despite a low correlation $(\mathrm{r}=31.5 \%, \mathrm{p}=0.048)$. This indicates the possibility of deteriorating clinical evolution in conditions of pain, and subsequently the possibility of higher costs involved in treatment ${ }^{5}$.

Depressive disorders occurred in $36.6 \%$ of participants, and these correlated significantly and positively with the STAI-T; which represents an important correlation ( $\mathrm{r}=61.3 \% ; \mathrm{p}<0.001)$. A review of scientific literature verified that depression is frequently associated with chronic pain, resulting in a lower quality of $\operatorname{life}^{21}$. The prevalence of depression in individuals with chronic pain is generally high, as verified by a Chinese study where $41.6 \%$ of patients with chronic pain were depressed ${ }^{18,22}$. Similar results were also found in a study in Taiwan, where depression disorders coexisted in $31.5 \%$ of participants with chronic pain ${ }^{23}$. Elbinoune et al. ${ }^{24}$ found that depression and anxiety were prevalent in individuals with chronic neck pain, and that these disorders were related to pain intensity. Also, Stubbs et al..$^{25}$ noted that any type of back pain, together with chronic pain in this region, are associated with an increased risk of anxiety, as well as depression and sleep disturbances.

The perception of pain may be amplified in the context of anxiety and depression. A study of patients with chronic low back pain has shown that the fear of painful exacerbations due to movements or the presence of catastrophizing ("emotional maladjustment") leads to more severe pain and greater disability ${ }^{26}$.
The associations between psychiatric conditions and chronic clinical conditions, such as chronic pain syndromes, are of major importance. While much of the research into psychiatric symptoms and chronic clinical conditions is centered on depression, with apparently significant associations between these conditions being identified, there is growing evidence that anxiety also coexists with such chronic conditions, and furthermore, coexists with their complications and vice versa ${ }^{17,25}$. Bener et al. ${ }^{27}$ observed a significant association between psychological stress and low back pain. In this study, anxiety disorders occurred in $9.5 \%$ of subjects with low back pain versus $6.2 \%$ of those without pain $(\mathrm{p}=0.007)$, and depression was observed in $13.7 \%$ of those with low back pain versus $8.5 \%$ of patients without pain $(\mathrm{p}=0.002)$.

In the present study, anxiety disorders were prevalent, and were even more frequent than depressive disorders, especially in terms of STAI-T, which were prevalent in $73.2 \%$ of elderly people with pain. This fact was also found when the scores of Davidson et al. ${ }^{17}$ for STAI-T screening were considered (58.5\%).

Studies have shown that mood disorders such as anxiety and depression often coexist with chronic pain $^{15,16,21,22}$. In Brazil, the authors Brasil and Pondé ${ }^{3}$ found that almost half of patients with chronic neuropathic pain $(46.3 \%$ of the studied sample), presented concomitant depressive and anxiety mood disorders, although there is no national data referring to the elderly population.

Both anxiety and depression are known to act as facilitators of the processing of pain at central levels. These disorders therefore participate in the pathogenesis of pain, sharing the same neurotransmitters (serotonin, noradrenaline, glutamate and adenosine) and sharing areas common in brain activation ${ }^{3,28}$.

In terms of anxiety, it is known that there are relatively stable individualdifferences in the tendency to react to situations perceived as threatening, and that such tendencies are considered as STAI-T2. Therefore, the idea remains that individuals with an anxious personality, not just an anxious emotional state (anxiety-state), suffer more chronic pain ${ }^{4,20}$. 
In general, it is expected that individuals with high STAI-T levels also have high STAI-S levels, as when the anxiety trait is present, the individual reacts to a wide range of situations as though they are very dangerous or threatening.

The present study had some limitations which should to be considered when interpreting the results. The cross-sectional design excluded the possibility of examining the causal relationships between pain, anxiety, and depression, and the sample was small, which does not allow the generalization of the results. However, the present study contributes unusual data involving chronic pain and mood disorders in older elderly people living in Brazil.

\section{REFERENCES}

1. Capela C, Marques AP, Assumpção A, Sauer JF, Cavalcante AB, Chalot SD, et al. Associação da qualidade de vida com dor, ansiedade e depressão. Fisioter Pesqui. 2009;16(3):263-68.

2. Castro MCC, Quarantini LC, Daltro C, Pires-Caldas M, Koenen KC, Kraychete DC, et al. Comorbidade de sintomas ansiosos e depressivos em pacientes com dor crônica e o impacto sobre a qualidade de vida. Rev Psiquiatr Clín. 2011;38(4):126-29.

3. Brasil ISP, Pondé MP. Sintomas ansiosos e depressivos e sua correlação com intensidade da dor em pacientes com neuropatia periférica. Rev Psiquiatr. 2009;31(71):24-31.

4. Asmundson GJG, Katz J. Understanding the cooccurrence of anxiety disorders and chronic pain: state-of-the-art. Depress Anxiety. 2009;26(10):888-901.

5. Gerrits MMJG, Vogelzangs N, Van Oppen P, Van Marwijk HWJ, Van der Horst H, Penninx BWJH. Impact of pain on the course of depressive and anxiety disorders. Pain. 2012;153(2):429-36.

6. Santos FC, Moraes NS, Pastore A, Cendoroglo MS. Dor crônica em idosos longevos: prevalência, características, mensurações e correlação com nível sérico de vitamina D. Rev Dor. 2015;16(3):71-175.

7. Kremer E, Atkinson JH, Ignelzi RJ. Measurement of pain: patient preference does not confound pain measurement. Pain. 1981;10:241-48.

8. Araújo LG, Lima DMF, Sampaio RF, Pereira LSM. Escala de Locus de controle da dor: adaptação e confiabilidade para idosos. Rev Bras fisioter. 2010;14(5):438-45.

\section{CONCLUSION}

High frequencies of anxiety disorders were identified in older elderly patients with chronic pain, and there were significant correlations between anxiety-trait and pain, as well as an association with depression. Frequent correlations between anxiety and chronic pain justify the need to apply varied and multidisciplinary measures, such as psychological intervention, in the therapeutic management of elderly people with persistent pain. Studies, which remain incipient, of this population group are important, due to its rapid growth and the prevalence of chronic and difficult to manage painful conditions.

9. Motta TS, Gambaro RC, Santos FC. Pain measurement in the elderly: evaluation of psychometric properties of the Geriatric Pain Measure - Portuguese version. Rev Dor. 2015;16(2):136-41.

10. Katz S, Akpom CA. A measure of primary sociobiological functions. Int J Health Serv 1976;6(3):493-508.

11. Lawton MP, Brody EM. Assessment of older people: self-maintaining and instrumental activities of daily living. Gerontologist 1969;9:179-85.

12. Alves LC, Rodrigues RN. Determinantes da autopercepção de saúde entre idosos do Município de São Paulo, Brasil. Rev Panam Salud Publica. 2005;17(5/6):333-41.

13. Paradela EMP, Lourenço RA, Veras RP. Validação da escala de depressão geriátrica em um ambulatório geral. Rev Saúde Pública. 2005;39(6):918-23.

14. Spielberger CD, Gorsuch RL, Lushene RE. STAI: manual for the State - Trait Anxiety Invetory. Palo Alto: Consulting Psychologists Press; 1970.

15. Spielberger CD, Gorsuch RL, Lushene RE. Inventário de ansiedade traço-estado (IDATE). Manual de psicologia aplicada. Rio de Janeiro:CEPA; 1979.

16. Spence JT, Spence KW. The motivationaI components of manifest anxiety: drive and drive stimuli. New York: Academic Press; 1966. 
17. Roy-Byrne PP, Davidson KW, Kessler RC, Asmundson GJG, Goodwin RD, Kubzansky L, et al. Anxiety Disorders and Comorbid Medical Illnes. Focus (Madison). 2008;6(4):467-85.

18. Pinheiro RC, Uchida RR, Mathias LAST, Perez MV, Cordeiro Q. Prevalência de sintomas depressivos e ansiosos em pacientes com dor crônica. J Bras Psiquiatr. 2014;63(3):213-9.

19. Pereira LV, Vasconcelos PP, Souza LAF, Pereira GA, Nakatani AYK, Bachion MM. Prevalência, intensidade de dor crônica e autopercepção de saúde entre idosos: estudo de base populacional. Rev Latinoam Enferm. 2014;22(4):662-9.

20. Haug TT, Mykletun A, Dahl AA. The association between anxiety, depression, and somatic symptoms in a large population: the HUNT-II study. Psychosom Med. 2004;66(6):845-51.

21. Lliffe S, Kharicha K, Carmaciu C, Stuck A. The relationship between pain intensity and severity and depression in older people: exploratory study. BMC Family Practice. 2009;10:1-7.

22. Ho PT, Li CF, Nq YK, Tsui SL, Nq KF. Prevalence of and factors associated with psychiatric morbidity in chronic pain patients. J Psychosom Res. 2011;70(6):541-7.

Received: March 9, 2016

Reviewed: September 14, 2016

Accepted: December 12, 2016
23. Huang T, Lee Y, Chong M. Psychological distress and help-seeking in patients with chronic pain. Psychol Asp Chronic Pain. 2005;(123):247-53.

24. Elbinoune I, Amine B, Shyen S, Gueddari S, Abougal $\mathrm{R}$, Hassouni NH. Chronic neck pain and anxietydepression: prevalence and associated risk factors. Pan Afr Med J. 2016;24:1-8.

25. Stubbs B, Koyanagi A, Thompson T, Veronese N, Carvalho AF, Mugisha MSJ, et al. The epidemiology of back pain and its relationship with depression, psychosis, anxiety, sleep disturbances, and stress sensitivity: Data from 43 low- and middle-income countries. Gen Hosp Psychiatr. 2016;43:63-70.

26. Elliott TE, Renier CM, Palcher JA. Chronic pain, depression, and quality of life: correlations and predictive value of the SF-36. Pain Med. 2003;4(4):331-9.

27. Bener A, Verjee M, Dafeeah EE, Falah O, Juhaishi TA, Schlogl J, et al. Psychological factors: anxiety, depression, and somatization symptoms in low back pain patients. J Pain Res. 2013;6:95-101.

28. Katz J, Rosenbloom BN, Fashler S. Chronic Pain, Psychopathology, and DSM-5 Somatic Symptom Disorder. Can J Psychiatr. 2015;60(4):160-7. 